\title{
Type Specimens of the Small-Headed Flies (Diptera, Acroceridae) in the Collection of the Zoological Institute of the Russian Academy of Sciences, St. Petersburg
}

\author{
E. P. Nartshuk ${ }^{a}$,, N. M. Paramonov ${ }^{a}$, and T. A. Suleymanova ${ }^{a}$ \\ a Zoological Institute, Russian Academy of Sciences, St. Petersburg, 199034 Russia \\ *e-mail: chlorops@zin.ru
}

Received August 10, 2021; revised August 17, 2021; accepted September 11, 2021

\begin{abstract}
A catalogue of the types (holotypes, paratypes, and a lectotype) of the species of the family Acroceridae described by L.F. Hildebrandt, F.D. Pleske, and E.P. Nartshuk, deposited in the collection of the Zoological Institute, Russian Academy of Sciences, St. Petersburg, Russia, is presented. Photographs of the specimens and labels of the holotypes and lectotype are given.
\end{abstract}

Keywords: Diptera, Acroceridae, holotypes, paratypes, lectotype, paralectotype, Zoological Institute of the Russian Academy of Sciences

DOI: $10.1134 / \mathrm{S} 0013873821060105$

In the present paper, the type specimens of the dipterans belonging to the family Acroceridae, deposited in the collection of the Zoological Institute of the Russian Academy of Sciences in St. Petersburg (ZIN), are considered.

The representatives of the family are medium-sized or large $(2.5-20 \mathrm{~mm})$ flies with tiny head and usually large spherical abdomen. In some flies (Oligoneura Bigot), the body is bent at a nearly right angle. The coloration is black, frequently with a white or yellow pattern against the black background. The family is distributed worldwide, except for the oceanic islands, and includes about 500 species in 48 genera. Approximately 40 species inhabit the Palaearctic Region, and 20 species mainly belonging to the genera Acrocera Meigen and Ogcodes Latreille are distributed in Russia (Nartshuk, 1988). The flies are rather rare in nature and, thus, are not numerous in the collections. Fossil representatives of the family are known since the Upper Jurassic. Four fossil genera and four species were described from Baltic amber. The adult flies are either nectarophagous with a long proboscis or do not feed. The larvae are endoparasites of spiders (Araneae) of the families Lycosidae, Theridiidae, and Gnaphosidae. Their development lasts from several months to several years.
The lists given below include all the type specimens of the species from the ZIN collection. The species names are listed in alphabetic order and followed by the quoted labels of the type specimens, their inventory numbers, and current names of the species.

Most of the original labels are written in Russian. The labels cited below are transliterated and translated in English for the holotypes, and only translated for the other specimens.

The photographs were taken with a Canon EOS 800D camera with a MP-E $65 \mathrm{~mm}$ objective and clamped and processed by Helicon Focus 6 software.

\section{Species Described by L.F. Hildebrandt}

albofimbriatus Hildebrandt, 1930 : 220 (Cyrtus) (Fig. 1). Holotype: female, a golden circle, "[provintsiya] Sych[uan], r[eka] Fubyankho, Shigaits, Shintyan [Shin'-Dyan'-Tszy bliz Kandina, Kitai] (in Cyrillic, $=$ Sichuan Province, Fu-bjan cho River, ShigaytsShintyan [Shin'-Dyan'-Tszy near Kangding, China]), 1[.]VIII[.]1893 (Potan[in])", handwritten identification label: "Cyrtus albofimbriatus typ Hild[ebrandt]," "Holotypus." The inventory number is INS_DIP_0000431. The current name is Paracyrtus albofimbriatus (Hilde- 


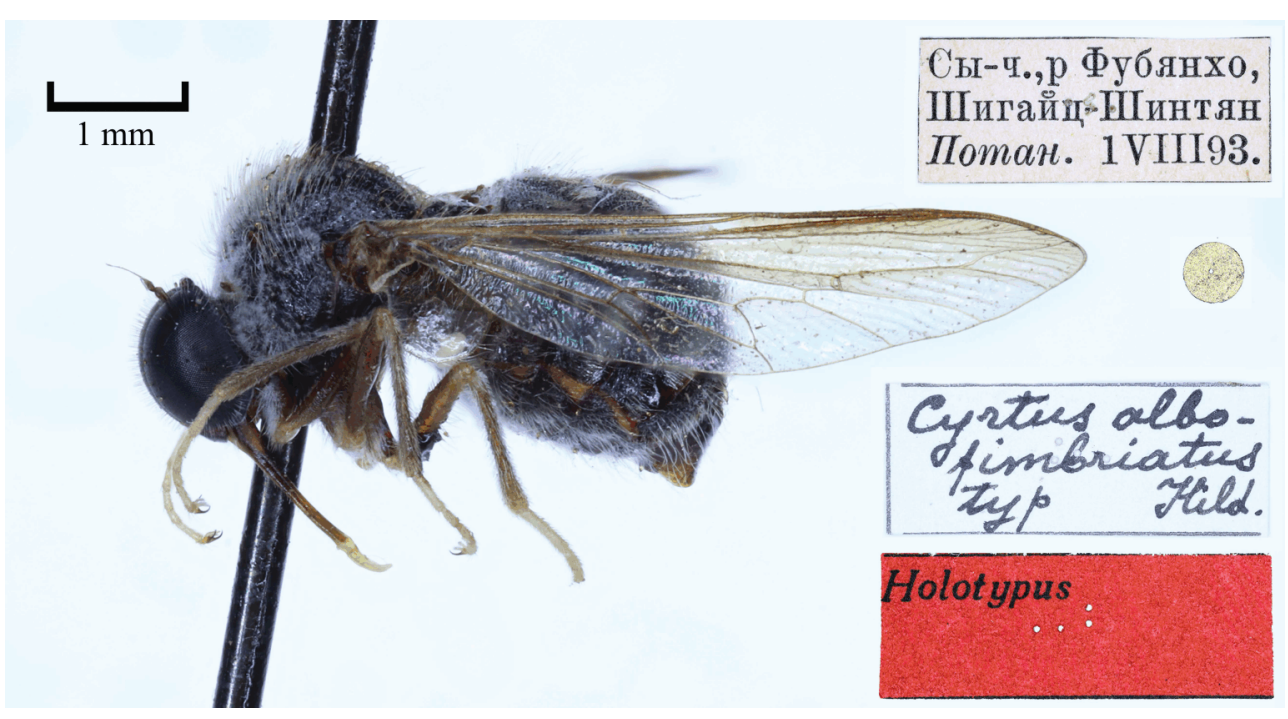

Fig. 1. Cyrtus albofimbriatus L.F. Hildebrandt, 1930, holotype. Photographs by N.M. Paramonov.

brandt, 1930) (Schlinger, $1972: 420)$. The holotype is well preserved.

\section{Species Described by F.D. Pleske}

altaica Pleske, 1930 : 171 (Acrocera) (Fig. 2). Holotype: male, a golden circle, "Ongudai, Altai, 10.VII.[18]98 (Berezovskii) (in Cyrillic)," handwritten identification label: "Acr[ocera] altaica $\mathrm{Pl}[\mathrm{e}] \mathrm{sk}[\mathrm{e}]$.
Typus," "Holotypus." The inventory number is INS_DIP_0000432. The date (23[.]VII) is given in the original description in the Gregorian chronology (Nartshuk, 1975 : 512) (data on labels in Julian chronology). The holotype is well preserved.

jacutensis Pleske, 1930 : 165 (Oncodes) (Fig. 3). Lectotype (Nartshuk, 1975 : 517): female, a golden circle, " $1 / 2$ v[ersty] ot st[antsii] Ugulyakh, Yakutsk[aya]
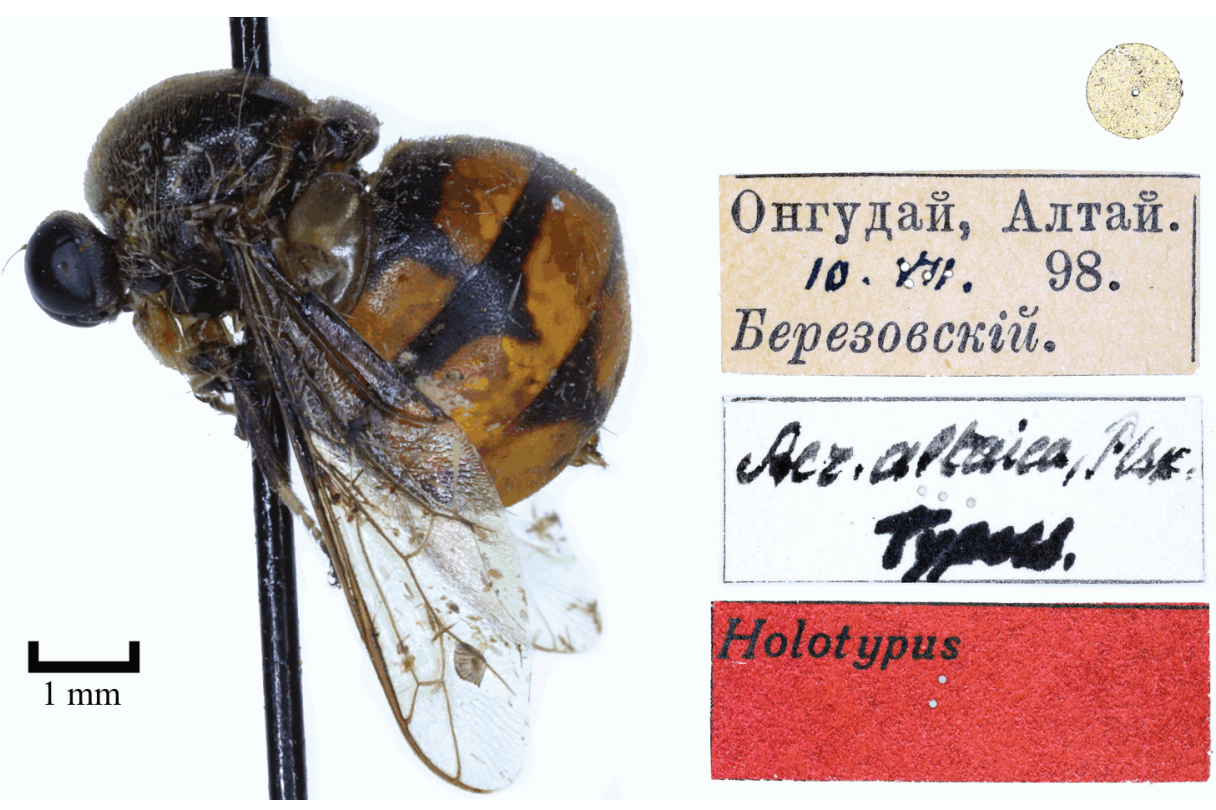

Fig. 2. Acrocera altaica Pleske, 1930, holotype. Photographs by N.M. Paramonov. 


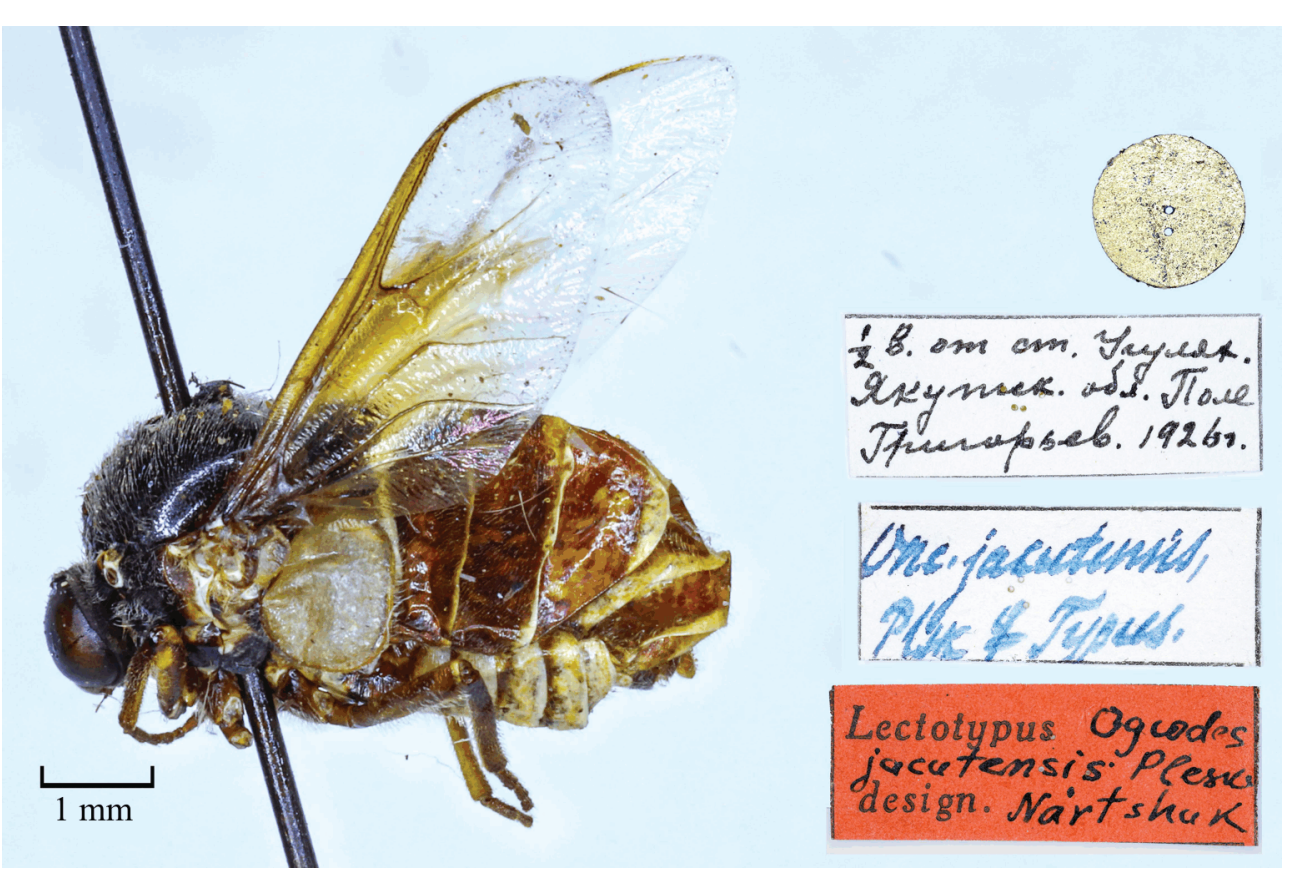

Fig. 3. Oncodes jacutensis Pleske, 1930, lectotype. Photographs by N.M. Paramonov.

obl[ast'], pole, $1926 \mathrm{~g}$ [od] (in Cyrillic, $=1 / 2$ verst [ a Russian unit of distance equal to 1.067 kilometers (0.6629 mile)] from Ugulyakh Station, Yakutsk Province, field, 1926), (Grigori'ev)," handwritten identification label: "Onc[odes] jacutensis $\mathrm{Pl}[\mathrm{e}] \mathrm{sk}[\mathrm{e}]$. Typus," handwritten identification label: "Lectotypus Ogcodes jacutensis Pleske, design. Nartshuk." The inventory number is INS_DIP_0000435. The current name is Ogcodes jacutensis (Pleske, 1930). Paralectotype: female, "Bele, Lake Teletskoe, Tomsk Government (one of the administrative subdivisions of Russia in 17081929) 28[.]VI[.][19]09 (Emeljanov)." The holotype is well preserved.

khamensis Pleske, 1930 : 172 (Acrocera) (Fig. 4). Holotype: male, a golden circle, "Tibet," "s[elo] Sanka, r[eka] Den-chyu, Kam', bas[sein reki] Goluboi (in Cyrillic, = Sanka Village, Dan Chu River, Kham, the Yangtze River basin), 17.IV.[19]01 (Kozlov)," handwritten identification label: "Acr[ocera] khamensis PI[e]sk[e], typus," "Holotypus." The inventory number is INS_DIP_0000436. The wings of the holotype are damaged.

mongolica Pleske, 1930 : 169 (Acrocera) (Fig. 5). Holotype: male, two golden circles, "Bichikte-Mi- shik-gun [ot urochishcha Bichigt-Ulan-Khada do monastyrya Mishik-Gun, bliz Delger-Khana, Tsentral'nyi aimak], Khalkha, Mong[oliya] (= Bichikte-Mishik-gun, from Bichigt-Ulan-Khad to the monastery of Mishik-Gun, near Delger-Khan, Töv Aimak, Khalkha, Mongolia), 1-7.IX.[1]925 ([P.K.] Kozlov)," handwritten identification label: "Acr[ocera] mongolica $\mathrm{Pl}[\mathrm{e}] \mathrm{sk}[\mathrm{e}]$, typus," "Holotypus." The inventory number is INS_DIP_0000438. In the original description, the collecting dates of the holotype and paratype were given in the Gregorion chronology. Since the holotype was designated in the description, designation of the same specimen as the lectotype is unnecessary (Nartshuk, 1975 : 512). Paratype: female, "Chelotai-buluk [Chulutain-Bulak], (Nyudun), E of Urga [Ulan-Bator], [Mongolia], 8[.]VIII[.][18]97 (Klements)." The holotype is well preserved.

sordida Pleske, 1930 : 170 (Acrocera) (Fig. 6). Holotype: male, a golden circle, "77398," "Kitai (in Cyrillic; = China)," "Przheval'skii (= Przhevalsky)," "Alashan'skie gory, kon[ets] VI - n[achalo] VII[.]1871 (=Alashan Mts., late VI - early VII.1871)," handwritten identification label: "Acr[ocera] sordida Pl[e]sk[e], typus," "Holotypus." The inventory number is INS DIP_0000442. The holotype is well preserved. 

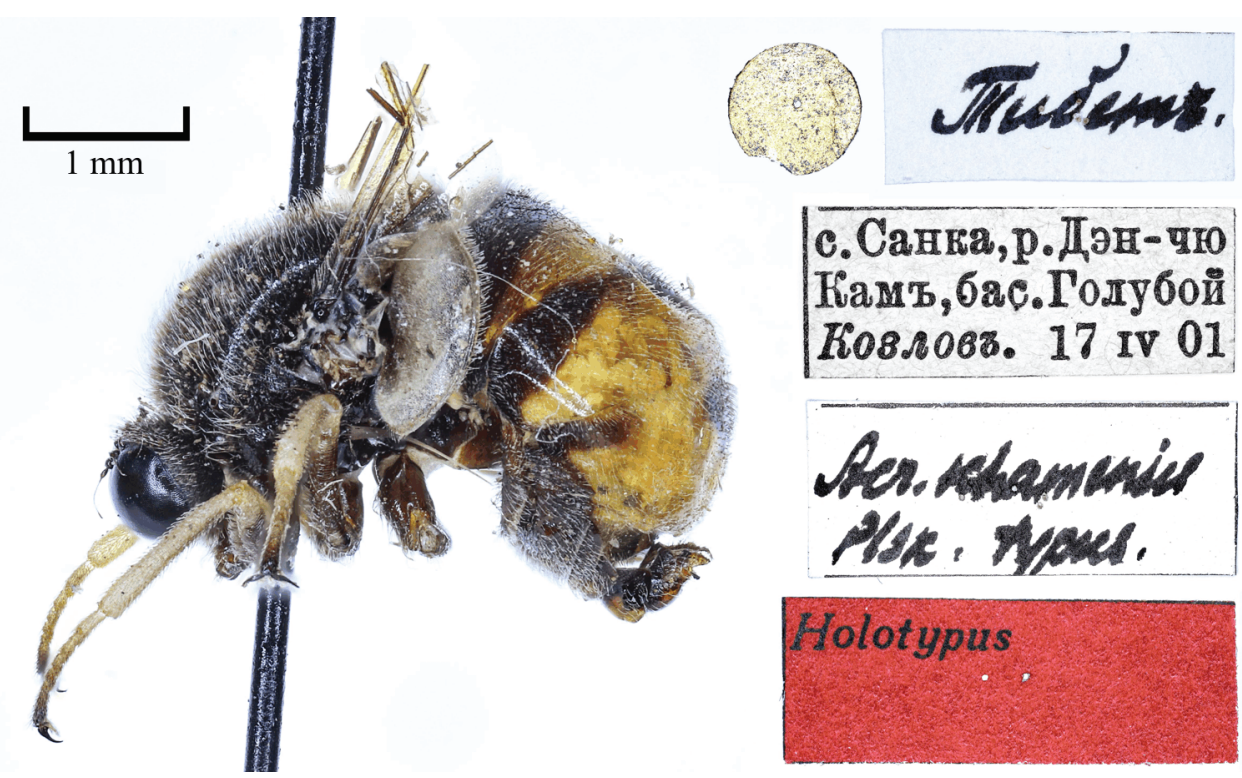

Fig. 4. Acrocera khamensis Pleske, 1930, holotype. Photographs by N.M. Paramonov.

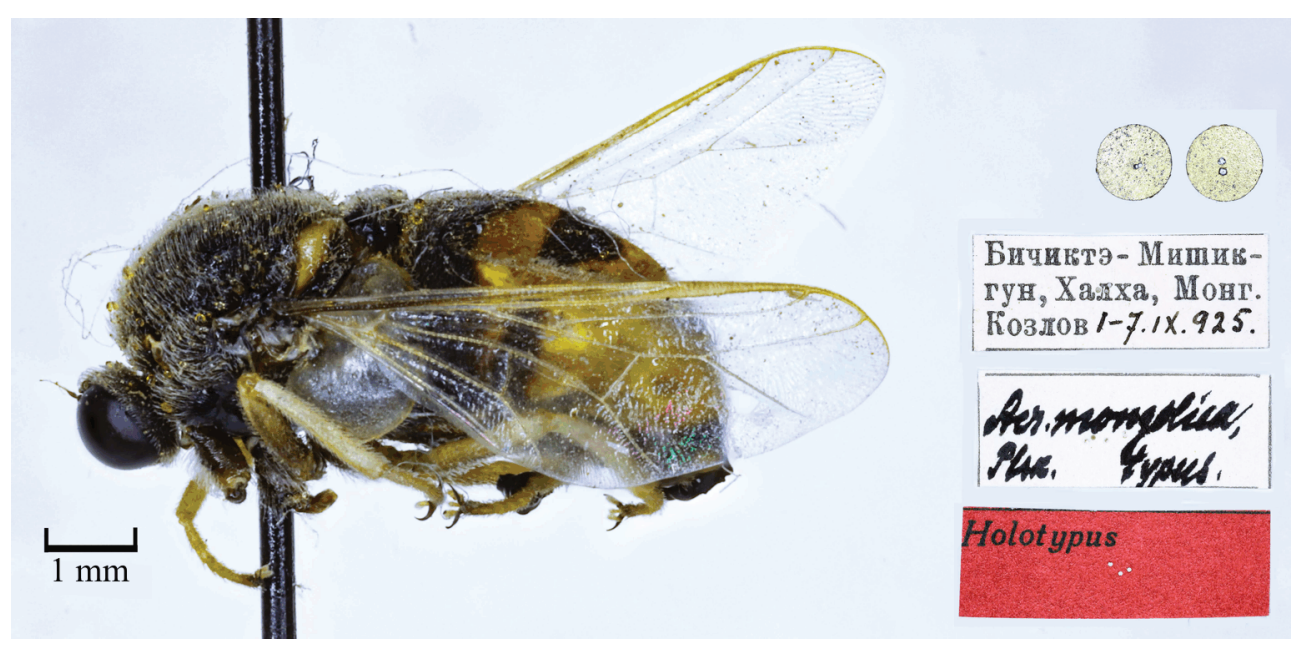

Fig. 5. Acrocera mongolica Pleske, 1930, holotype. Photographs by N.M. Paramonov.

transbaicalica Pleske, 1930 : 172 (Acrocera) (Fig. 7). Holotype: male, a golden circle, "Chita, Zabaik[al'e] (= Transbaikalia), 11-18.VI.[1]912 (Gitel'man)," handwritten identification label: "Acr[ocera] transbaicalica sp. n. Th. Pleske det." (written by A.A. Stackelberg, not by F.D. Pleske), "Holotypus." The inventory number is INS_DIP_0000445. The holotype is well preserved.

trifasciata Pleske, 1930 : 169 (Acrocera) (Fig. 8). Holotype: female, a golden circle, "Shaku [Shakhkukh], yu[zhnyi] skl[on] El'br[El'bursskii] $\mathrm{khr[ebet],} \mathrm{8-}$
10000', Pers[iya] (= Shaku [Shakhkukh], southern slope of the Alborz Mt. Range), 26.VI[.][19]14 (Kiritshenko)," handwritten identification label: "Acr[ocera] trifasciata P1[e]sk[e], typus," "Holotypus." The inventory number is INS_DIP_0000446. The apex of the abdomen is cut off; the slide is missing.

\section{Species Described by E.P. Nartshuk}

acroventris Nartshuk, 1982 : 413 (Ogcodes) (Fig. 9). Holotype: female, [Sakhalin Island], "Yu[zhno]-Sakha- 


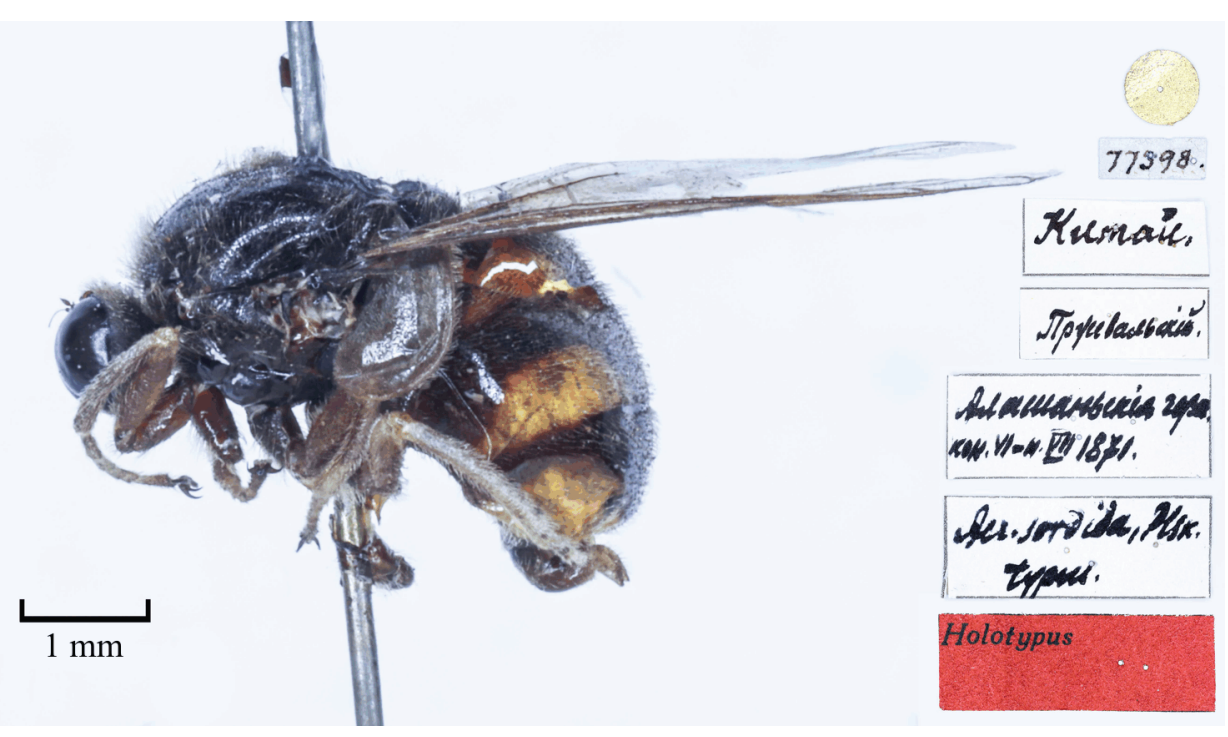

Fig. 6. Acrocera sordida Pleske, 1930, holotype. Photographs by N.M. Paramonov.

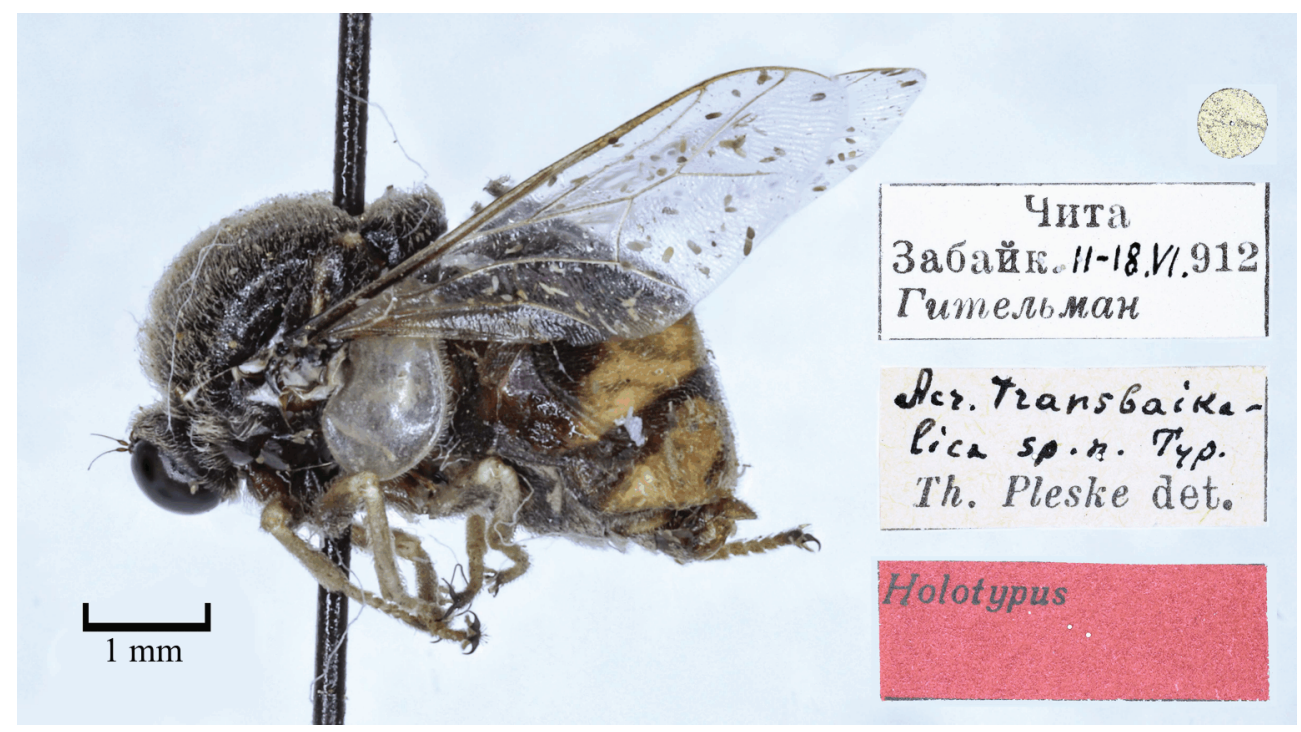

Fig. 7. Acrocera transbaicalica Pleske, 1930, holotype. Photographs by N.M. Paramonov.

linsk, okr[estnosti] (= environments of the city of Yuzhnosakhalinsk), 19.VII.[1]955 (Violovich)," handwritten identification label: "Holotypus Ogcodes acroventris Nartshuk." The inventory number is INS_DIP_0000430. The legs are partly missing.

asiaticus Nartshuk, 1975 : 514 (Ogcodes) (Fig. 10). It was described as a subspecies $O$. zonatus asiaticus Nartshuk, 1975. Holotype: male, "Mongoliya, GobiAlt[aiskii] aimak, $12 \mathrm{~km} \mathrm{YuZ} \mathrm{Tsogta} \mathrm{(=} \mathrm{Mongolia,}$
Gobialtay Aimak, 12 km SW of Tsogt), 15.VII.[1]970 (Nartshuk)," “pr (= preparation). № 20186," handwritten identification label: "Holotypus Ogcodes zonatus asiaticus Nartshuk." The inventory number is INS_DIP_0000433. A microvial with the genitalia preparation in glycerol with the same number is deposited in the collection of the Diptera Department. Paratypes: 3 males and 1 female, same locality; 1 male, 'Kamen'Rybolov, Lake Khanka, Yuzhno-Ussuriisk Territory, 27[.]VII[.][19]08 (Cherskii)," a microvial with the geni- 


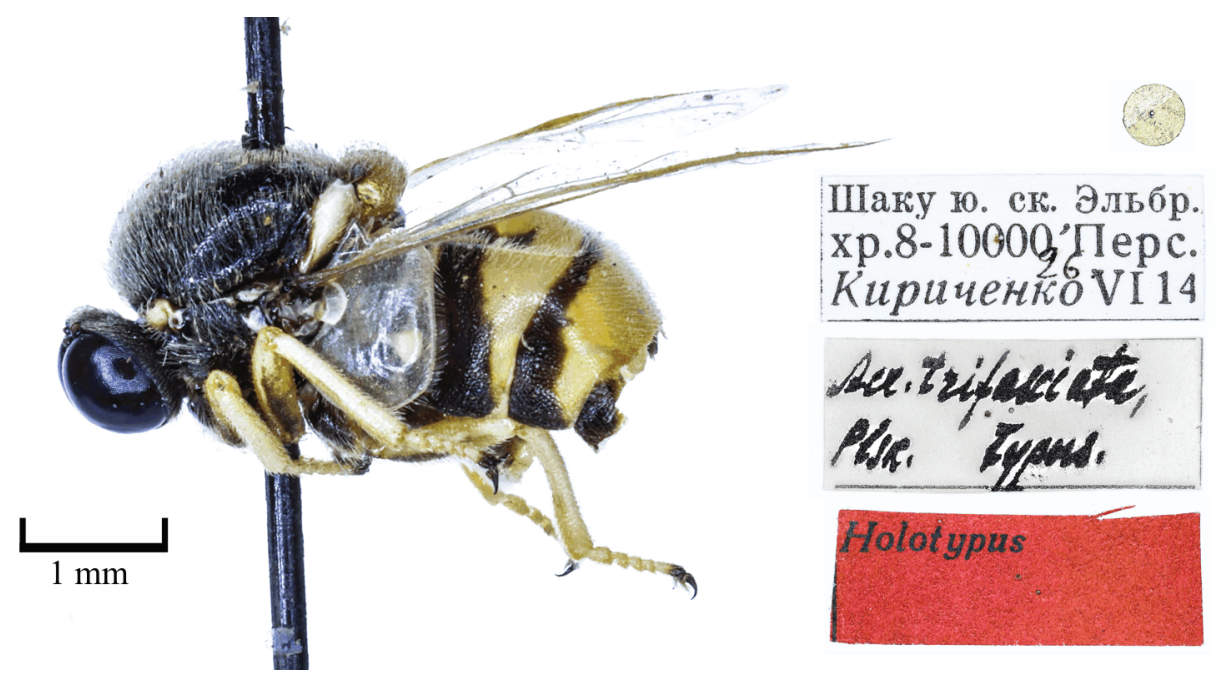

Fig. 8. Acrocera trifasciata Pleske, 1930, holotype. Photographs by N.M. Paramonov.

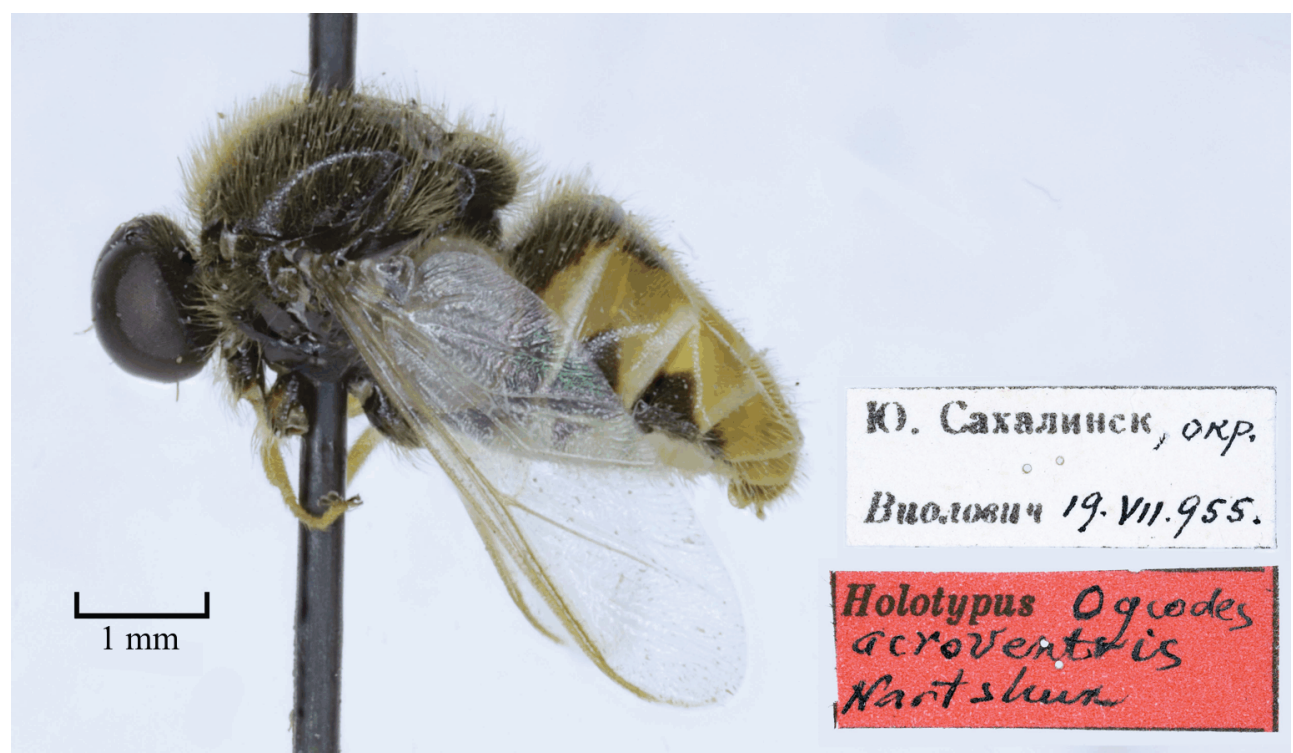

Fig. 9. Ogcodes acroventris Nartshuk, 1982, holotype. Photographs by N.M. Paramonov.

talia is pinned under the specimen; 1 male, "Astrabad' [Gorgan], Persia [Iran], 2.V[.][19]14 (Kiritshenko);" 1 male, "Astrabad, Persia, 22.IV[.][19]14 (Kiritshenko);" 2 males, “Astrabad, Persia, 26.IV[.][19]14 (Kiritshenko)," a microvial with the genitalia is pinned under one specimen; 1 male, "Mongolia, between Ulukhem and Urgailyk Village, 10-11.VI.[19]14 (Tomashinskii)," actually, the collecting locality is in the Republic of Tuva, Russia; 1 male, "Mongolia, Uvs Aimak, Lake Uvs, $50 \mathrm{~km}$ E of Ulangom, 6.VIII.[1]970
(Nartshuk);" 1 male, "Mongolia, Hovd Aimak, NariinBulak Spring, Ikh-Khavtgiin-Nuru Mt. Range, 24.VII.[1]970 (Nartshuk)," "pr[eparat] (= microvial with the genitalia) № 20183;" 1 male, "Mongolia, Gobialtay Aimak, Adzh-Bogdo Mt. Range, $40 \mathrm{~km}$ NNE of Altai, 19.VII.[1]970 (Nartshuk)," " pr[eparat] № 20181;" 1 male, "Mongolia, Gobialtay Aimak, Adzh-Bogdo Mt. Range, 40 km NNE of Altai, 19.VII.[1]970 (Zaitsev)," “pr[eparat] № 20184;" 1 male, [Bayan-Hongor Aimak] "Tuin-gol River middle course, Khalkha area, Mon- 


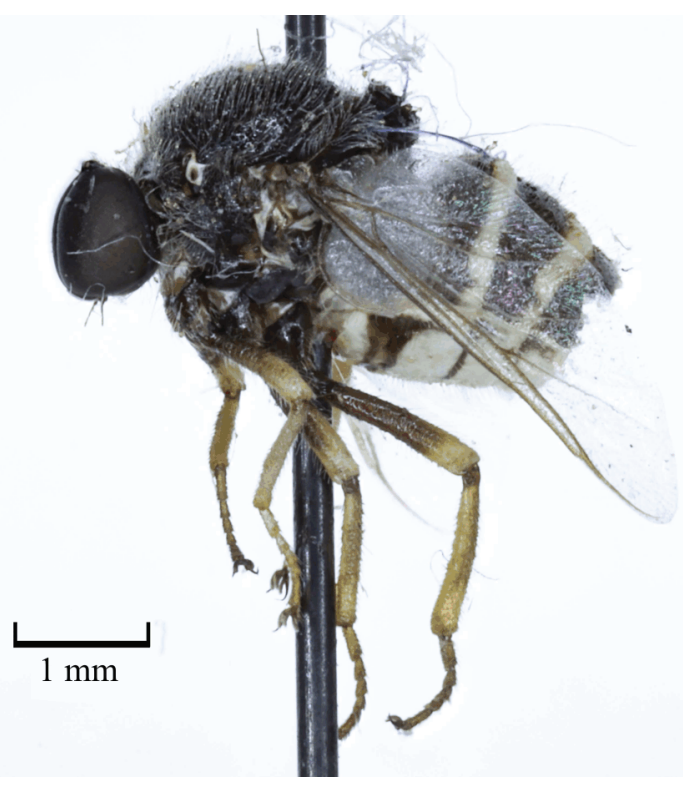

МОНГОЛИЯ, ГОбИ-Алт. аймак, І2 км 108 цогта

Нарчук 15.УП.970

Hp.N20186

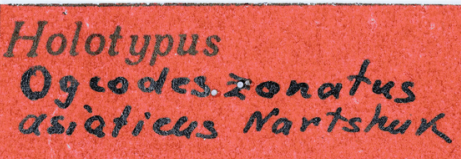

Fig. 10. Ogcodes zonatus asiaticus Nartshuk, 1975, holotype. Photographs by N.M. Paramonov.

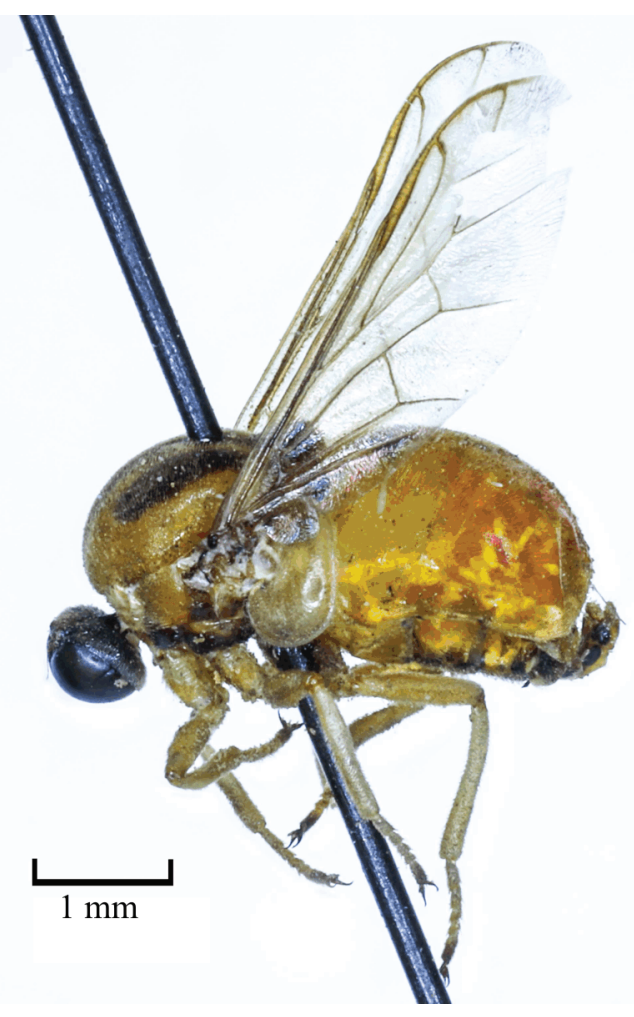

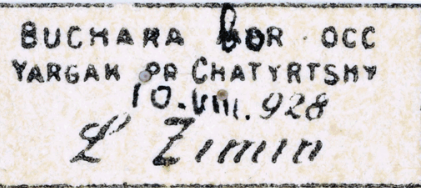

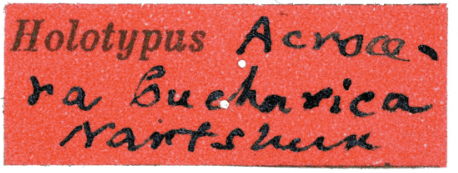

Fig. 11. Acrocera (Acrocerina) bucharica Nartshuk, 1982, holotype. Photographs by N.M. Paramonov. 


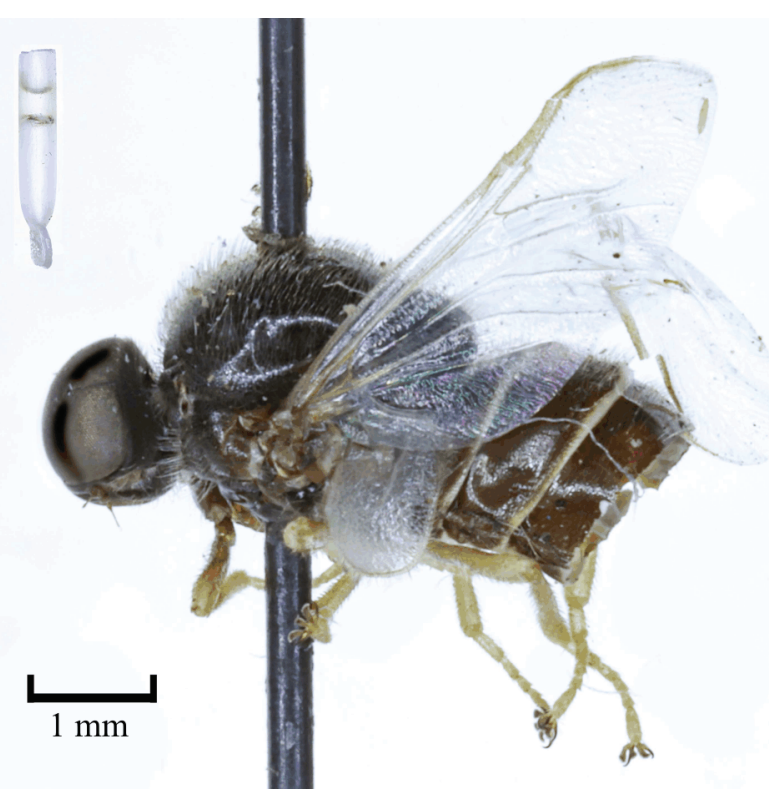

Cимоново Amур. обл.
75 км W Cвободного
3иновьев 22.vı. 959.
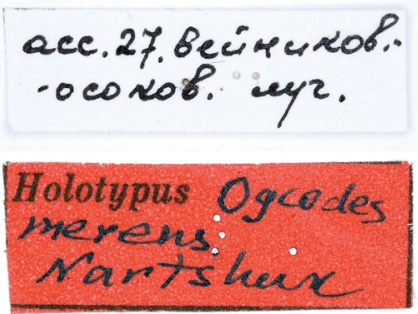

Fig. 12. Ogcodes merens Nartshuk, 1982, holotype. Photographs by N.M. Paramonov.

golia, 28[.]VII[.][19]26 (Kiritshenko)," “pr[eparat] Jargak, pr. Chatyrtshy [Yargak bliz Khatyrchi, Samar№ 20183;" 1 male, "Mongolia, Bayan-Hongor Aimak, kandskaya obl.] (in Cyrillic, = Yargak near Khatyrchi, 80 km WSW of Bayan-Hongor, 10.VII.[1]970 (Emel- Samarkand Province), 10.VIII.[1]928 (Zimin)," handjanov);" 1 male, "Zavchan-Niederung ca $20 \mathrm{~km}$ Žar- written identification label: "Holotypus Acrocera buchagalan, 47 $20^{\prime} \mathrm{N} 95^{\circ} 48^{\prime} \mathrm{E}, 1450 \mathrm{~m}, 22-24$.VI.1964," de- rica Nartshuk." The inventory number is INS posited in Museum für Naturkunde der DIP_0000434. The current name is Acrocera bucharica Humboldt-Universität, Berlin, Germany. The current Nartshuk (Nartshuk, 1982). The holotype is well prename is Ogcodes asiaticus Nartshuk (Nartshuk, 1982). The holotype is well preserved.

bucharica Nartshuk, 1982 : 412 (Acrocera (Acrocerina)) (Fig. 11). Holotype: female, "Buchara bor.-occ., served.

merens Nartshuk, 1982 : 414 (Ogcodes) (Fig. 12). Holotype: male, "Simonovo, Amur[skaya] obl[ast'], $75 \mathrm{~km} \mathrm{~W}$ Svobodnogo (in Cyrillic, = Simonovo,

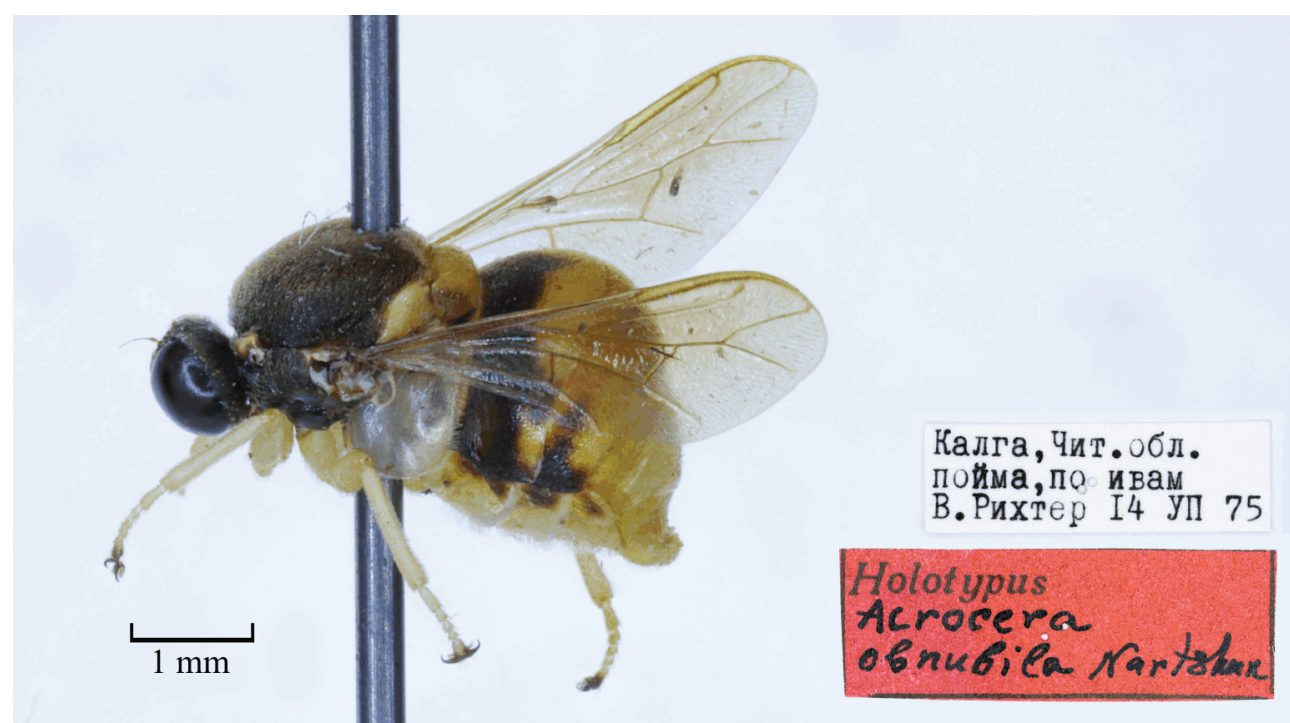

Fig. 13. Acrocera obnubila Nartshuk, 1979, holotype. Photographs by N.M. Paramonov. 


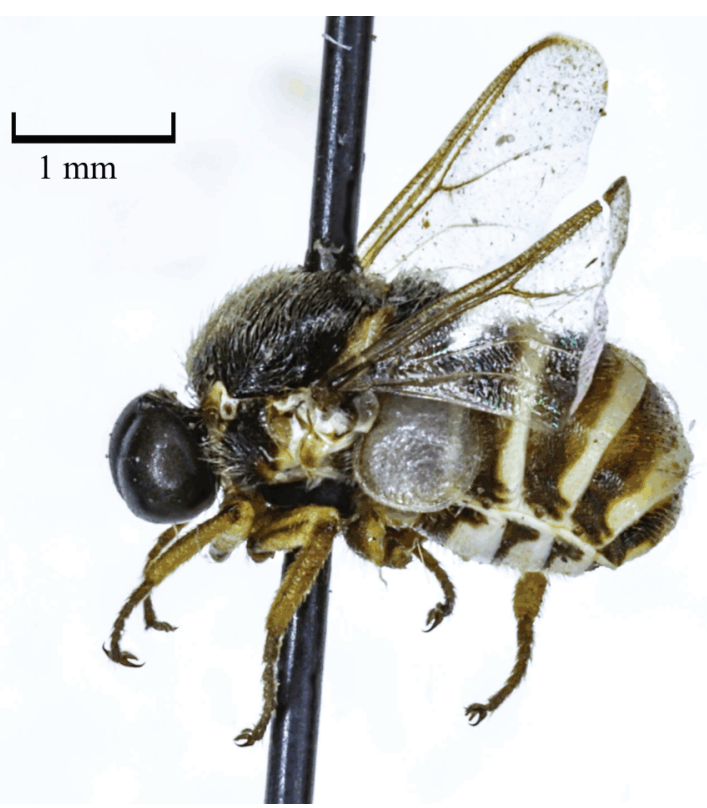

Qттук, 1630 м юж. бер. Нссык-Куль Нарчук 14 VIII 969

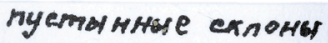

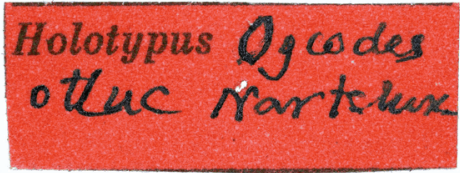

Fig. 14. Ogcodes ottuc Nartshuk, 1982, holotype. Photographs by N.M. Paramonov.

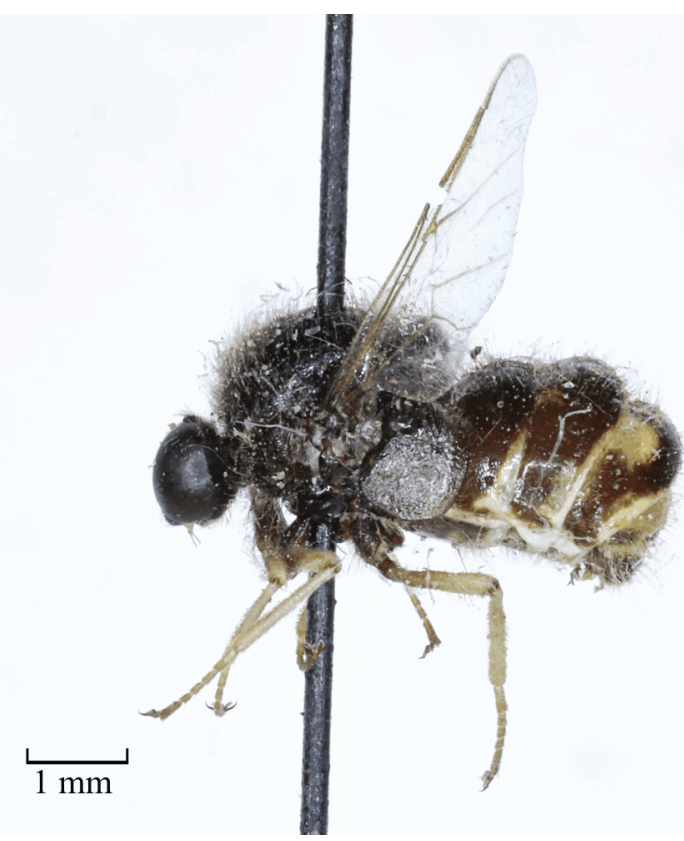

к. Путуп, д. Пянджа Ю. Памир, $2600 \mathrm{~m}$ 3ariseb 1.VIII.964

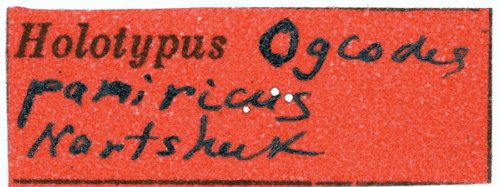

Fig. 15. Ogcodes pamiricus Nartshuk, 1982, holotype. Photographs by N.M. Paramonov.

Amurskaya Province, $75 \mathrm{~km}$ W of Svobodnoe), 22.VII. [1]959 (Zinovi'ev)," "ass[otsiatsiya] 27. veinikovo-osokov[yi] lug (in Cyrillic, = association 27, reedgrasssedge meadow)," handwritten identification label: "Holotypus Ogcodes merens Nartshuk." The inventory number is INS_DIP_0000437. The abdomen is cut off; a microvial with the genitalia is pinned under the specimen. The holotype is well preserved.

obnubila Nartshuk, 1979 : 425 (Acrocera) (Fig. 13). Holotype: male, "Kalga, Chit[inskaya] obl[ast'], poima, po ivam (= Kalga, Chita Province, flood plain, on wil- 


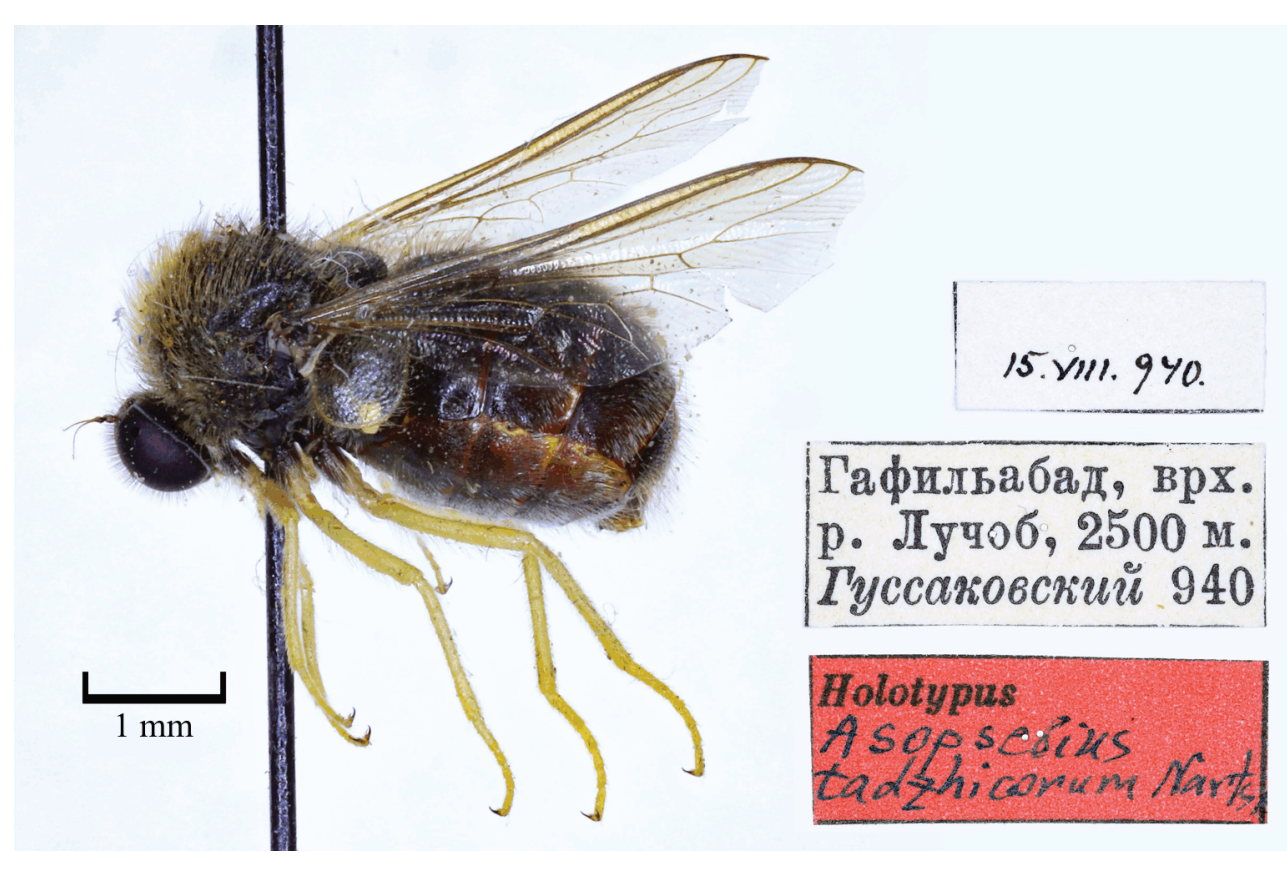

Fig. 16. Asopsebius tadzhicorum Nartshuk, 1982, holotype. Photographs by N.M. Paramonov.

lows), 14.VII.[19]75 (V. Richter)," handwritten identification label: "Holotypus Acrocera obnubila Nartshuk." The inventory number is INS_DIP_0000439. Paratype: male, "Kozlovo, Chita Province, black-birch forest edge, 17[.]VII[.][19]75 (V. Richter)." The holotype is well preserved.

ottuc Nartshuk, 1982 : 415 (Ogcodes) (Fig. 14). Holotype: male, [Kirgiziya (= Kyrgyzstan)] "Ottuk, 1630 m, yuzh[nyi] ber[eg] [oz.] Issyk-Kul' (in Cyrillic, = Ottuk, $1630 \mathrm{~m}$, southern shore of Lake Issyk-Kul), 14[.]VIII[.][1]969 (Nartshuk)," “pustynnye sklony (= desert slopes)," handwritten identification label: "Holotypus Ogcodes ottuc Nartshuk." The inventory number is INS_DIP_0000440. Paratype: male, same locality. The holotype is well preserved.

pamiricus Nartshuk, 1982 : 414 (Ogcodes) (Fig. 15). Holotype: male, [Tadzhikistan (= Tajikistan)] " $\mathrm{k}[$ ishlak] Putup, d[olina] Pyandzha, Yu. Pamir (= Putup Village, Pyandzh River valley, Southern Pamir), 2600 m, 1.VIII.[1]964 (Zaitsev)," handwritten identification label: "Holotypus Ogcodes pamiricus Nartshuk." The inventory number is INS_DIP_0000441. Paratype: male, same locality. The holotype is well preserved. tadzhicorum Nartshuk, 1982 : 411 (Asopsebius) (Fig. 16). Holotype: female, [Tadzhikistan (= Tajikistan)] 'Gafil'abad, v[e]rkh[ov'e] r[eki] Luchob (= Gafil'abad, upper course of the Luchob River), 2500 m, [1]940 (Gussakovskii)," “15.VIII.[1]940,” handwritten identification label: "Holotypus Asopsebius tadzhicorum Nartshuk." The inventory number is INS DIP_0000443. Paratypes [Tajikistan]: 1 female, "Gafil'abad, upper course of the Luchob River, $2500 \mathrm{~m}$, [1]940 (Gussakovskii)," “23.VIII.[1]940;” 1 female, "Kvak, 2000 m, 35 km N Stalinabad] [= Dushanbe], 17[.]VIII[.][19]37 (Gussakovskii);" 1 female, "Kondara Gorge, $1100 \mathrm{~m}$, Varzob River valley, Tajikistan, 17.IX.[19]37 (Gussakovskii).” The holotype is well preserved.

tarsalis Nartshuk, 1975 : 513 (Acrocera) (Fig. 17). Holotype: male, "Mongoliya, Tsentral'nyi aimak, sev[ernyi] skl[on] Bogdo-ula bliz Ulan-Batora (= Mongolia, Töv Aimak, northern slope of Bogdo-Ula near Ulan-Bator), 29.VI.[1]967 (Kerzhner),” “prep[arat] № 20190," handwritten identification label: "Holotypus Acrocera tarsalis Nartshuk." The inventory number is INS_DIP_0000444. A microvial with the number 20190 containing the genitalia in glycerol is deposited in the collection of slides of the Diptera Department. In the 


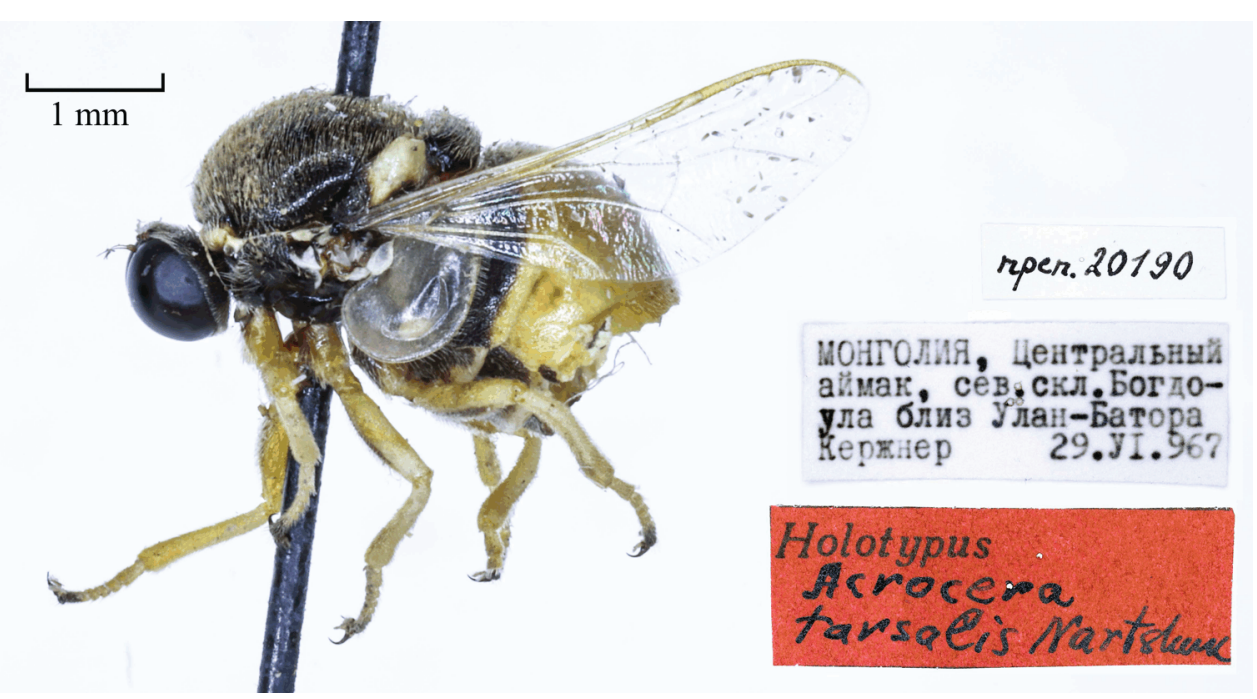

Fig. 17. Acrocera tarsalis Nartshuk, 1975, holotype. Photographs by N.M. Paramonov.

original description, the date 27.VI was erroneously given (Nartshuk, $1975: 513$ ). The holotype is well preserved.

\section{FUNDING}

The study was based on the collection of the Zoological Institute, Russian Academy of Sciences (project no. AAAAA19-119020690082-8).

\section{COMPLIANCE WITH ETHICAL STANDARDS}

The authors declare that they have no conflict of interest. All the applicable international, national, and institutional guidelines for the care and use of animals were followed. All the procedures performed in studies involving animals were in accordance with the ethical standards of the institution or practice at which the studies were conducted.

\section{OPEN ACCESS}

This article is licensed under a Creative Commons Attribution 4.0 International License, which permits use, sharing, adaptation, distribution and reproduction in any medium or format, as long as you give appropriate credit to the original author(s) and the source, provide a link to the Creative Commons license, and indicate if changes were made. The images or other third party material in this article are included in the article's Creative Commons license, unless indicated otherwise in a credit line to the material. If material is not included in the article's Creative Commons license and your intended use is not permitted by statutory regulation or exceeds the permitted use, you will need to obtain permission directly from the copyright holder. To view a copy of this license, visit http://creativecommons.org/licenses/by/4.0/.

\section{REFERENCES}

Hildebrandt, L.F., Description of a new species of the genus Cyrtus (Diptera, Acroceridae) from China, Ezhegod. Zool. Muz. Akad. Nauk SSSR, 1930, vol. 31, no. 2, p. 219.

Nartshuk, E.P., Contribution to the fauna of small-headed flies (Acroceridae, Diptera) of the Mongolian People's Republic, in Nasekomye Mongolii, Vyp. 3 (Insects of Mongolia, Issue 3), Leningrad: Nauka, 1975, p. 511.

Nartshuk, E.P., New data on small-headed flies (Diptera, Acroceridae) of the Mongolian People's Republic, in Nasekomye Mongolii, Vyp. 6 (Insects of Mongolia, Issue 6), Leningrad: Nauka, 1979, p. 424.

Nartshuk, E.P., A review of small-headed flies (Diptera, Acroceridae) of the fauna of the USSR with a description of a new genus and new species, Entomol. Obozr., 1982, vol. 61, no. 2, p. 404.

Nartshuk, E.P., Family Acroceridae, in Catalogue of Palaearctic Diptera. Vol. 5. Athericidae-Asilidae, Soós, Á. and Papp, L., Eds., Budapest: Akadémiai Kiadó, 1988, p. 186.

Pleske, Th., Revue des espèces palèarctiques de la famille des Cyrtidae (Diptera), Konowia, 1930, vol. 9, no. 2, p. 156.

Schlinger, E.J., New East Asian and American genera of the "Cyrtus-Opsebius" branch of the Acroceridae (Diptera), Pac. Insects, 1972, vol. 14, no. 2, p. 409. 